This item was submitted to Loughborough's Research Repository by the author.

Items in Figshare are protected by copyright, with all rights reserved, unless otherwise indicated.

\title{
The use of bioreactors as in vitro models in pharmaceutical research
}

PLEASE CITE THE PUBLISHED VERSION

http://dx.doi.org/10.1016/j.drudis.2013.05.016

\section{PUBLISHER}

(c) Elsevier Ltd.

\section{VERSION}

SMUR (Submitted Manuscript Under Review)

\section{LICENCE}

CC BY-NC-ND 4.0

\section{REPOSITORY RECORD}

Ginai, Maaria, Robert Elsby, Christopher J. Hewitt, Dominic Surry, Katherine Fenner, and Karen Coopman. 2014. "The Use of Bioreactors as in Vitro Models in Pharmaceutical Research". figshare.

https://hdl.handle.net/2134/14245. 
This item was submitted to Loughborough's Institutional Repository (https://dspace.lboro.ac.uk/) by the author and is made available under the following Creative Commons Licence conditions.

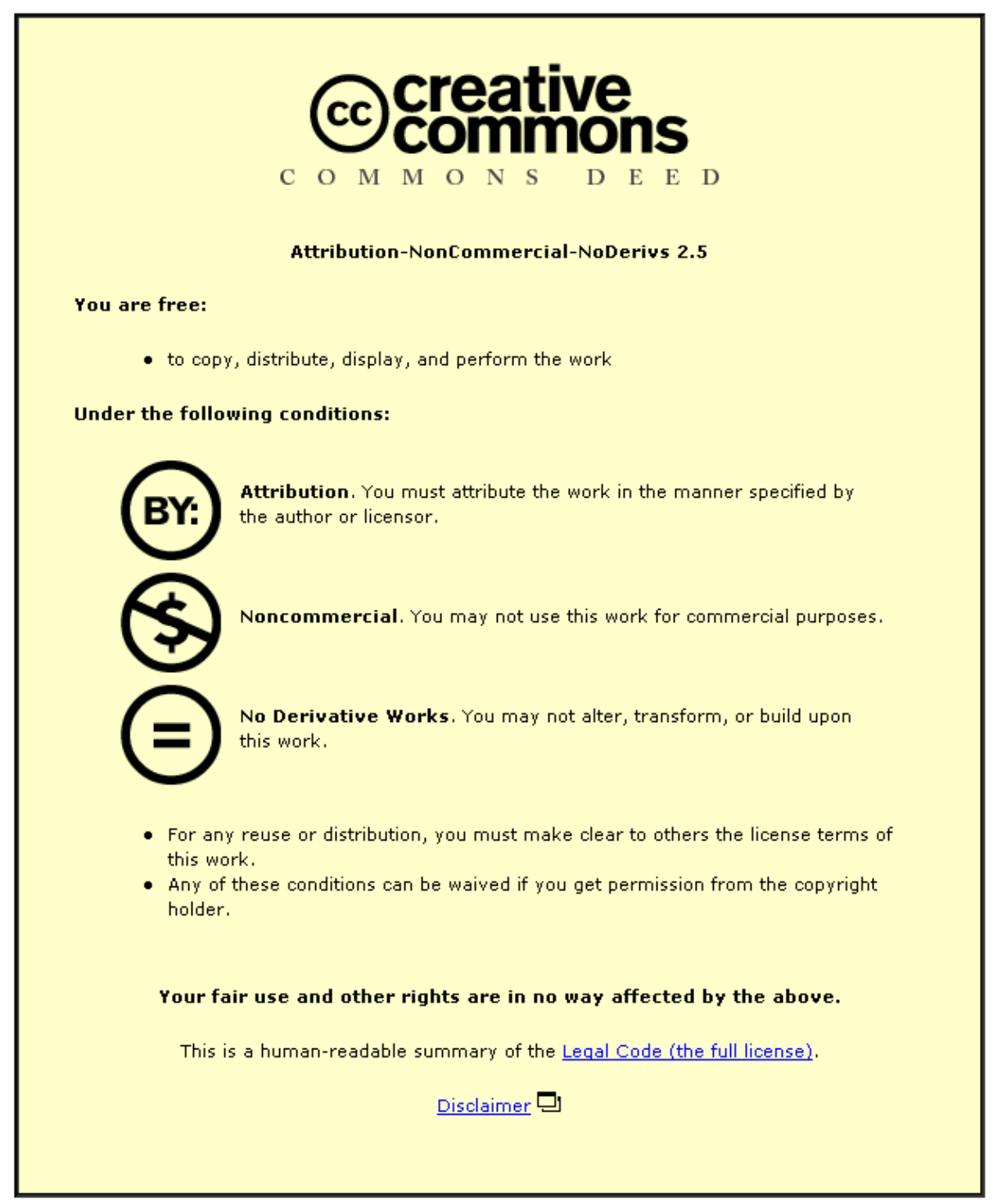

For the full text of this licence, please go to: http://creativecommons.org/licenses/by-nc-nd/2.5/ 


\section{The use of bioreactors as in vitro models in pharmaceutical research}

Maaria Ginai ${ }^{1}$, Robert Elsby ${ }^{2}$, Christopher J Hewitt ${ }^{1}$, Dominic Surry ${ }^{2}$, Katherine Fenner ${ }^{2}$ and Karen Coopman ${ }^{1}$

${ }^{1}$ Centre for Biological Engineering, Department of Chemical Engineering, Loughborough University, Loughborough, LE11 3TU, UK

${ }^{2}$ In Vitro In Silico ADME, Global DMPK, AstraZeneca R\&D Alderley Park, Mereside, Macclesfield, SK10 4TG, UK

Corresponding author: Dr. Karen Coopman (k.coopman@lboro.ac.uk); telephone +44

(0)1509 222513; fax +44 (0)1509 223923

Keywords: In vitro model, bioartificial systems

\section{Word Teaser}

The development of dynamic 3D bioreactor based systems as in vitro models for use in DMPK studies.

\section{Author Biographies}

Maaria Ginai graduated with a first Class Bachelors degree with honours in Biomedical Science from the University of Kent (UK) in 2010. She is currently studying a BBSRC CASEfunded PhD at the Centre for Biological Engineering at Loughborough University in the area of bioartificial device progression to in vitro models for use in the pharmaceutical industry. This project is supported by AstraZeneca.

Christopher J. Hewitt has a first Class Bachelors degree in Biology from Royal Holloway College, University of London (UK) and a PhD in Chemical Engineering from the University of Birmingham (UK). He is Director of the f7.3M EPSRC Doctoral Training Centre in Regenerative Medicine and co-founder of the $\mathrm{f} 2 \mathrm{M}$ Centre for Biological Engineering at Loughborough University (UK). He also leads the Cell Technologies research group whose work spans the Engineering/Life science interface seeking to understand the interaction of the organism with the engineering environment within such diverse areas as microbial fermentation, bio-transformation, cell culture and mostly recently regenerative medicine bioprocessing.

Karen Coopman has a first Class Bachelors degree in Pharmacology from the University of Bristol (UK) and a PhD from the Department of Pharmacy and Pharmacology at the University of Bath (UK). She was appointed to a lectureship at Loughborough University, where she is the Operations Manager of the EPSRC-funded Doctoral Training Centre in Regenerative Medicine. She co-leads the Cell Technologies research group within University's Centre for Biological Engineering and is currently a member of the EPSRC's Early Career Forum in Manufacturing Research. The overarching themes of Karen's research are the manufacture of cellular therapies and the use of cells in the drug discovery process. 


\begin{abstract}
Bringing a new drug to market is costly in terms of capital and time investments, and any development issues encountered in late stage clinical trials may often be due to in vitro - in vivo extrapolations (IVIVE) not accurately reflecting clinical outcome. In the discipline of drug metabolism and pharmacokinetics (DMPK), current in vitro cellular methods do not provide the 3D structure and function of organs found in vivo, so new dynamic methods need to be established to aid improvement of IVIVE. This review will highlight the importance of model progression into dynamic systems for use within drug development, focussing on devices developed currently in the areas of the liver and blood-brain barrier, and the potential to develop models for other organ systems such as the kidney.
\end{abstract}

Currently, the pharmaceutical industry balances the stringent testing of drugs and products against soaring costs and return on investments risks. Bringing a new drug to market will, presently, on average cost $\$ 1.3$ billion over 12 years [1] [2] with pre-clinical in vitro testing consuming around half of the total development time [2]. Moreover, many new chemical and biological entities (NCEs/NBEs) which fail late stage human testing give evidence that pharmacological and toxicity data from in vitro cell based assays are not always predictive of the clinical situation [3]. Due to these financial and time commitments, there is great emphasis within the industry to develop newer and more reliable in vitro and pre-clinical methods to accompany or replace the existing methods of NCE/NBE investigations.

In vitro models, particularly cell based versions are utilised in various areas of drug discovery, such as target identification and validation using disease models, compound screening and basic cytotoxicity using static cultures, through to ADMET (absorption, distribution, metabolism, excretion and toxicology) studies on lead compounds. While highthroughput cell based assays have revolutionised the efficiency and speed at which compounds can be screened, ADMET models ideally should be an accurate representation of the physiological or pathophysiological state, which may be lacking in 2D static cultures. Tissue engineering advances show promise in the development of models with organised structure and cell types similar to in vivo. However the dynamic aspect of in vitro models is yet to fully be addressed, although it is starting to be investigated with the use of three dimensional bioreactors seeded with cells.

Within the pharmaceutical industry the absorption, distribution, metabolism and excretion properties of NCEs are typically investigated as part of drug metabolism and pharmacokinetic (DMPK) science. These DMPK properties are optimized within drug discovery so that an NCE has the right clinical profile, e.g. ideally a high oral bioavailability, an elimination half-life that enables a once daily dosing regimen, sufficient exposure at the target tissue and an absence of drug-drug interaction (DDI) potential [4]. In vitro 2D cell 
based models are routinely used within pharmaceutical research to investigate the DMPK properties of absorption (Caco-2, derived from human colon carcinoma cells), distribution (MDCKII-MDR1, derived from canine kidney cells) and metabolism/excretion (hepatocytes) for NCEs. More recently some three dimensional models have started to be investigated to assess their utility in studying aspects of ADME, namely the bioartificial liver (distribution/metabolism/elimination), the blood brain barrier model (distribution) and the bioartificial kidney (excretion). This review will therefore focus on the potential of bioartificial devices that have been developed for therapeutic use to progress to pharmaceutically relevant in vitro models for use in DMPK studies.

\section{Limitations of current 2D systems}

In vitro cell based models offer several advantages over the majority of cell free methods as they do not require purification of the target protein, they immediately select against compounds that are generally cytotoxic or cannot permeate cell membranes, and enable measurement of functional transport activity that is more representative of the physiological state [5]. Using primary human cells in these assays is the ideal gold standard [6]; however freshly isolated cells, cell cultures or tissue fragments cannot be used to study effects that occur over a longer time period due to the loss of functional integrity from drug transporter loss and enzyme depletion after a few hours [7][8]. In addition, primary human cells are a scarce and precious resource. For these reasons immortalised cell lines, such as (transfected) MDCKII-MDR1 or Caco-2 are often utilised in favour of primary cells. Such cells are relatively inexpensive and easy to propagate, especially in high throughput systems, however due to the genetic transformation process aspects of the original cell that are important to ADMET studies may be lost such as transporter expression and function, and cell adhesion molecules [8].

Although relatively simple and effective when using the appropriate cell type, ' $2 D$ ' in vitro cell based assays encounter the traditional problems of static culture; a constantly changing environment due to nutrient depletion and metabolic waste accumulation. Strategies to improve such systems have been introduced based on mimicry of the natural physiological environment of the organ in question. The reestablishment of heterotypic cellcell and cell-extracellular matrix interactions through co-cultures and sandwich cultures of cells respectively have proven useful in the progression of in vitro model development for a number of tissue types including the liver [9] [10], brain [11] and lung [12]. These models show improved functionality and growth compared to their single culture counterparts, whilst keeping their ease of propagation and use compared to primary cell cultures, which is imperative when developing long term in vitro models for pharmaceutical applications.

Perfusion systems of isolated organs or tissue fragments offer the closest ex vivo model of the natural physiological state, alleviating the problems encountered with static 
culture, maintaining 3D architecture and prolonging the functionality, heterogeneity, structural complexity and cell-cell interactions [13]. However, the shortage of organs available and the costs and difficulties of maintaining primary cells ex vivo make perfusion cultures unsuitable as a routine in vitro cell based system.

\section{Moving towards 3D systems}

The development of 3D constructs for pharmaceutical research now encompasses a variety of systems and devices. 3D cell culture with cell types native to a specific organ that are grown on natural scaffolds such as collagen, decellularised scaffolds or synthetic biodegradable scaffolds, present a bridge between 2D culture and the in vivo cellular environment. 3D devices for pharmaceutical research, with structural complexity and native functionality are now becoming available, however these cultures are difficult to maintain in vitro and still lack the vascular component of tissues. Extracellular matrix (ECM) coatings on scaffolds such as polymer scaffolds which release growth factors have been investigated to aid cell attachment, growth and partially represent the native environments which can have profound effects on the morphology, behaviour and functions of cells needed in drug discovery processes, but further work is needed to progress these cultures for use as models [14].

Bioartificial devices combine flow through systems, usually a form of simple plug flow bioreactor, with cells, thereby mimicking both the dynamic and cell specific aspects of native tissues [13]. They are being incorporated in the pharmaceutical industry due to the potential payoff of getting more drugs to market [15]. As will be discussed further in the following sections, these devices are being developed from clinically used systems, and whilst they offer cellular and environmental similarities, most systems currently lack the complex architecture and microenvironments seen in 3D constructs.

\section{Status of bioreactors in the development of in vitro models}

Bioreactors are utilised in a range of applications, from being used in the production of biopharmaceuticals to applications in tissue engineering such as cell expansion, generation of 3D tissue constructs and direct organ support devices [16] (see Table 1). Unlike 2D static culture, bioreactors provide a controllable environment in terms of $\mathrm{pH}$, temperature, nutrient supply and shear stress for any cells or cellular constructs incorporated into them. However key limitations in 3D culture such as mass transfer of oxygen and nutrients to cells still apply. For example, cardiac muscle tissue contains a high density of cells and has a high oxygen demand which in vivo is supplied by a dense network of capillaries through the tissue. To gain a better understanding of the native environment of cardiac tissue and its influence on the synchronously contracting cardiac constructs, a 
bioreactor-based model has been developed [17]. Incorporated into this device are rodent cardiomyocytes and fibroblasts grown on scaffolds with a parallel array of perfused channels to mimic the capillary network. Blood was mimicked by supplemented media and the model used to assess a number of parameters such as the impact of perfusion rates of oxygen on viable cell density to the define the conditions needed to culture cardiac constructs with clinically relevant thickness [18].

Hollow fibre and perfusion systems in particular are widely used in the generation of in vitro models. In addition to allowing users to investigate the impact of environmental conditions on cells, they can also be used to model pharmacological interactions of drugs with cells in infectious states [19] or model disease states [20].

Progression from these systems has generated multi-compartmental bioreactors that mimic the physiological environment more closely. As well as being used clinically [21], they are being utilised as in vitro models, like the scaling down of a 3D perfusion multicompartment hollow fibre liver bioreactor for use in in vitro pharmacological studies [22]. This bioreactor consists of three interwoven sets of hollow fibre, two for counter current medium perfusion and one for gas supply (Fig 1). Primary human liver cells (both parenchymal and non-parenchymal) are co-cultured in the extra capillary space (ECS), and have been shown to exhibit prolonged CYP enzyme activity when maintained for over 3 weeks, enabling long term pharmacological studies to be carried out. Hollow fibre bioreactor based models are also being developed for the blood-brain barrier (BBB) and kidney. It is important to critically assess the individual features of established systems so that optimised models for pharmaceutical research can be generated, and this will be the focus of the remainder of the review. 


\section{Perspectives from established systems used within pharmaceutical research}

\section{Bioartificial Liver (BAL) devices}

The liver is the main excretory organ within the body, but as well as eliminating waste products through the bile, it carries out a variety of highly specialised functions; oxidative detoxification, intermediate metabolism and supply of nutrients, modulation of immune and hormonal systems and protein and macromolecule synthesis [6]. Disruption in these functions due to liver disorders such as acute or chronic liver failure can lead to a possible $90 \%$ mortality rate if essential hepatic functions are not restored during the critical phase of liver failure [23]. Therefore, there is great emphasis on the development of reliable in vitro models to assess drug interactions and pharmacological responses to prevent drug induced acute liver toxicity, and to accurately model liver disease states for the development of NCEs targeting disease induced liver failure.

Bioartificial liver (BAL) devices have gone through many iterations whilst being developed as an extracorporeal device for the treatment of liver failure [24]. Early flat plate and monolayer bioreactors exhibited uniform cell distributions and microenvironments, but presented complex scale up issues and a low surface area to volume ratio [25] [26]. Perfused beds/scaffolds promote 3D architecture of seeded cells, which when considering the complex architecture of the liver, is an immense advantage. The cells showed improved metabolic and synthetic function compared to cells cultured in a spinner flask [27], however, exposure to shear forces and non-uniform perfusion of medium require an improved bioreactor design. Conventional hollow fibre cartridges offer increased surface area for attachment and immunoisolation of cells when seeded in the ECS [28]. Cells are also protected from shear as medium flows through the fibres. However non-uniform cell distribution along the fibres is a common problem, and although being beneficial in terms of support and improved cell growth and performance if adapted to the specific cell type [29], membranes can present a physical barrier against the transport of nutrients and metabolites. As mentioned previously, development from standard hollow fibre bioreactors to multi-compartmental devices such as that in Fig 1 has been a natural progression considering the native architecture of the liver and has been utilised for both clinical and pharmacological applications [22]. 


\section{Cell Sources}

Hepatocytes are the primary choice for use in BAL systems as they are recognized to be the closest cellular model to the liver [30] [31], and carry out most of the in vivo metabolic processes including the synthesis and excretion of albumin, metabolism of amino acids, urea production and the processing and elimination of drugs and toxins. Phase I and phase II drug metabolising enzymes are crucial in the processing of drugs within the liver, so preservation of these enzymes within a model is essential to reproduce cellular environments in vivo.

Cell lines have frequently been utilised for in vitro studies due to prolonged cell survival and ease of maintenance compared to primary hepatocytes. Popular liver derived cell lines such as the HepG2/C3A cell line derived from hepatomas have been used in pharmacological studies, recently being utilised in microfluidic bioreactors to examine the sensitivity of the models in response to various xenotoxins [32] [33]. However, compared to primary hepatocytes, functionality is often lost or altered in these cell lines [6]. For instance, phase I enzymes were expressed at significantly lower levels in HepG2 cells relative to primary human hepatocytes [34]. Therefore, primary cells would be the ideal for incorporation into a pharmacologically relevant in vitro model. However, recent work has demonstrated the successful incorporation of a HepaRG human hepatoma cell line into a 3D BAL device, in which metabolic and transporter functionalities of the cells are preserved from a mere few hours in suspension to at least one week in the 3D device, thereby enabling performance of longer-term in vitro pharmacological studies[35] [36] [37].

Primary porcine hepatocytes have been widely incorporated into BAL devices [38] [39] as they are readily available, are able to maintain differentiated metabolic functions under certain culture conditions, provide a high yield of cells [40] and have a similar metabolic profile to human hepatocytes [41]. The environmental triggers that sustain differentiated hepatic function in vitro however, have not been fully characterised [42].Utilising porcine cells addresses the problem of finding a sustainable source of hepatocytes; however, it would be important to obtain cells derived from a human source to establish a representative model of the natural physiological environment for in vitro pharmacological studies in both normal and diseased states.

Primary human adult hepatocytes are considered to be the gold standard for biocompatibility and functionality within BAL systems [6] [43], but exhibit a rapid, timedependent, general loss of function in vitro [7]; including reduced cytochrome P450 and other biotransformation enzyme activities [44] and the down regulation of liver enriched transcription factors such as CCAAT/enhancer binding protein alpha [43]. However, the use of complex chemically defined media has allowed hepatocytes to go through a number of cycles in culture as well as stabilize hepatocyte morphology, survival, and liver-specific functions [45] [38] [46] [43]. Co-culture with non-parenchymal cells has also shown to preserve liver specific functions including initiating physiological reorganisation of cells and 
the distribution of canalicular transporters similar to the pattern found in vivo [22]. The mechanisms behind these changes are not fully understood, but highly conserved signalling pathways are thought to be involved [9].

There is also limited availability of adult human hepatocytes due to their acquisition from liver biopsies, which has presented problems with utilising this source in clinically used devices as the number of cells needed for seeding a BAL for the treatment of hepatic failure is quite large, approximately $2 \times 10^{10}$ [26] [47]. However the number of cells needed for bioreactor based models are approx. $3 \times 10^{8}$ per device [22], which could be attained with minimal culture in vitro.

\section{Device designs and functionality}

Within the native liver, hepatocytes are ordered in a 3D lobular network of hexagonal constructs, surrounding a central blood vessel. Individual cells possess polarity between the apical domain interfacing with bile canaliculi and a basal domain interfacing with the sinusoid, helping localise specific functions. During culture, hepatocytes flatten and spread upon attachment, whether grown on a flat surface or a scaffold. Although cell-cell junctions can be formed, the cytoskeleton is largely disrupted, and leads to loss of cell polarity, and ultimately liver specific functions [6].

Nonetheless, C3A cells and primary porcine cells have been utilised within hollow fibre bioreactors (HFBs) in clinically tested devices. The Extracorporeal Liver Assist Device (ELAD) consists of a dual pump dialysis system connected to one or more hollow fibre cartridges seeded with C3A cells in the ECS. Blood is ultrafiltered and pumped through fibres, with plasma flowing through the ECS. This direct interaction allows cellular processes to occur before the ultrafiltrate is filtered by a dual membrane to remove cells and cellular debris and returned back into the blood stream [48].

The liver has an oxygen rich environment, fed by the hepatic arteries and portal vein. Unsurprisingly, an improvement in functionality of C3A cells in HFBs was noted when red blood cells were added in culture medium [49], highlighting that an adequate oxygen supply is a prerequisite for the maintenance of hepatocytes in vitro. Considering this, the Excorp medical bioartificial liver support system (BLSS) incorporates an oxygenator and heat exchanger along with a blood pump and HFB seeded with primary porcine hepatocytes in the ECS [50]. Whole blood flows through the fibre, protecting the cells from host immunological responses [39].

Another BAL, the modular extracorporeal liver support system (MELS) has attempted to take into account the biliary system of the liver which excretes conjugated bilirubin and metabolites. Hollow fibre bundles, seeded with human hepatocytes from discarded donor livers are incorporated alongside a detoxification module for removing albumin bound 
toxins. This provides an inlet of plasma and contact with hepatocytes in the ECS, an outlet of plasma, and hydrophobic membrane bundles for gas exchange inside the bioreactor [51]. The structure of the seeded bioreactor module is an early iteration of the multicompartmental bioreactor being developed for in vitro pharmacological studies by Gerlach et al (described above and in Fig 1).

These systems, although showing positive biochemical changes in patients and maintaining patients through to transplantation, show no significant effect on survival, and therefore can be assumed to be unsuitable replicates of the environment in vivo. Aspects such as co-culture of non-parenchymal and parenchymal cells, efficient oxygenation of cells and the presence of a biliary system for the removal of toxic protein bound substances and other metabolites should be taken forward in the generation of both efficient in vitro models, as has been demonstrated in the multi-compartmental liver bioreactor (Fig 1), and clinically relevant medical devices.

\section{Use of BALs in DMPK studies}

Bioreactor-based models are currently being integrated into the DMPK process, initially assessing the functionality of cells within the systems relative to drug transporter and metabolic enzyme expression and function. When investigating the metabolism of diclofenac, freshly isolated human hepatocytes were found to produce $90 \%$ less hydroxydiclofenac, the hydroxylated product of diclofenac generated directly by the cytochrome P450 enzyme CYP2C9, after a 3-day culture in 2D conditions compared to a high level of metabolites from human hepatocytes in the multi-compartmental bioreactor described above [35] [22]. The major intermediary diclofenac metabolite, diclofenac acyl glucuronide (produced from the glucuronidation of diclofenac by UDPglucuronosyltransferase (UGT) enzymes before hydroxylation by the P450 enzyme CYP2C8), was found to be absent in human hepatocyte suspensions, but present in the hepatocyte seeded bioreactor, possibly due to the bioreactor system mimicking the in vivo environment and allowing the efflux of metabolites away from the cells, thereby avoiding further metabolism. Overall, the relative levels of the metabolites found in the suspensions versus the 3D cultures were similar; however, all human in vivo metabolites were detected in the bioreactor culture, whereas one major in vivo metabolite was not present in the hepatocyte suspension. In addition the biotransformation capacity of the hepatocytes within the bioreactor was retained for at least a week, providing a good model for metabolite investigations from slowly metabolised drugs [35]. The activity of CYP3A4 was demonstrated in the 3D bioreactor system by monitoring the metabolism of atorvastatin acid (ATA) to its 2- and 4- hyroxylated metabolites [36], and for HepaRG cells in the 3D system by monitoring midazolam, which indicated that CYP3A4 activity was retained for up to 2 weeks [48]. This retention of CYP3A4 activity is longer than that currently available in other in vitro models. 
Transporter expression is also a key aspect in the functionality of hepatocytes for DMPK screens. Within the bioreactor, immunohistochemical staining of multidrug resistance associated protein (MRP2) and multidrug resistance protein (MDR1), both bile canicular efflux transporters, showed expression, localisation and distribution similar to native liver tissue for at least 2 weeks within the bioreactor [37] [22]. The basolateral uptake transporter organic anion transporting polypeptide 1B1 (OATP1B1) expression has also been investigated on hepatocytes within the 3D system being preserved for 9 days, Functional activity of OATP1B1 was demonstrated by the transport of substrates estradiol- 17 $\beta$-Dglucuronide (E17 $\beta G$ ) and ATA in the presence and absence of the inhibitor estrone-3sulphate (E3S), and was retained for 7 days compared to the decrease of functional activity of OATP1B1/1B3 in plated primary human hepatocytes after just 2 hours [52] [36]. When assessing drug-drug interactions, OATP1B1 is a vital hepatic transporter to evaluate, as it is inhibited by many commonly used drugs, and is responsible for the targeted uptake of the widely prescribed statins to their site of action [53]. This has been demonstrated by similar increases in the elimination half-life of ATA in the presence and absence of OATP1B1 inhibitors, with a 2.7 fold increase in the presence of rifampin [54], and a 1.7 fold increase in the presence of E3S within the bioreactor model. The difference in these values had been attributed to experimental setup and potencies of the two inhibitors, and it is also been noted that the major limitation of this model lies in the variable quality of isolated human hepatocytes from different donors [36]. However, these initial studies into the functionality of drug transporters and metabolic enzymes clearly establish the potential of this model for use throughout the DMPK process.

For both the medical devices and in vitro models highlighted above there are currently no standardised criteria to define the efficiency and efficacy of these systems. Furthermore, any criteria applicable to a device will be partly dependent on the type of bioreactor used, i.e. hollow fibre systems require tight monolayers of cells on the extra luminal side of the fibre membrane. However, cellular metabolic functions and enzymatic and transporter retention is paramount in all bioartificial liver systems. From the clinically relevant devices mentioned above, there is little focus on the performance of cells, and factors used to determine the efficiency of the systems before being used in clinical studies are not clearly stated. Devices that have been utilised for pharmaceutical (DMPK) research go further in defining the criteria used to assess the models, such as monitoring metabolic activity via albumin synthesis, lactate dehydrogenase or aspartate aminotransferase, and drug metabolising enzymatic activity via administration of drugs with cytochrome P450dependent metabolism, as well as drug transporter functionality and visualisation by inhibitor transport assays and staining [22] [35] [36] [37] [52] [53] [54]. With the progression of these systems, both medical and in vitro models, standardised criteria defining the performance relative to native conditions of the above mentioned factors should be produced. 


\section{Blood brain barrier models}

The BBB is one of the most important lines of defence against infections in the brain, acting as a physical and metabolic barrier between the central nervous system (CNS) and systemic circulation and maintaining homeostasis within the brain. The capillary structure is distinct from those found in peripheral tissues with the presence of tight junction proteins between endothelial cells, the restriction of transcellular movement of molecules and contact of endothelial cells with astrocytes to provide support [55], protection from hypoxia and aglycemia and to separate capillaries from neurons [56].

The decreased paracellular permeability of the BBB, while possessing multidrug transporters such as P-glycoprotein, prohibits the transport of large drug molecules into the CNS, presenting the need for a reliable in vitro model for ADME studies. Existing models have not been characterised as well as liver devices, partly due to their lack of clinical relevance regarding the generation of an extracorporeal device, but also due to the complexity of cell alignments and functionality within the model. However, like the BAL devices, HFBs have been developed and utilised as 'dynamic' models of the BBB [57].

\section{Model designs}

Unlike liver models and bioartificial devices, there is no one cell type that can be incorporated to mimic the BBB. Most models reported in the literature use two cell types; endothelial cells and glial cells (astrocytes). Early models simply used mono/co-cultures of endothelial cells (EC) alone or with glial cells cultured on transwell plates. This approach is attractive due to its simplicity, however, primary ECs lose their BBB properties in vitro due to the absence of stimuli that are normally present in vivo [57]. Furthermore, specific transporters such as P-gp are down-regulated in the absence of astrocyte-derived soluble factors leading to abnormal permeability across the monolayer [58]. This de-differentiating process may also be accelerated by non-physiological conditions such as the presence of serum on both sides of the polarised EC monolayer instead of only on the luminal surface in vivo. Co-culture models incorporating glial cells mimic the in vivo situation more closely, demonstrated by the increased expression of brain endothelial marker enzymes, transporters, and an increased trans-endothelial electrical resistance (TEER) across the barrier indicative of a 'tight' monolayer. This model is effective for studies around the function of the BBB and processes and interactions between the ECs and the glia [57]. However, for a replicative model of the BBB, factors such as shear stress, which is vital to promote growth inhibition and differentiation of ECs and allows trafficking of metabolic fuels to the brain, should be incorporated into animal based models before ideally progressing into human based models to allow direct extrapolation of data from studies, and functional and physiological mimicry of the human BBB in vivo [59]. 
Dynamic (flow based) models incorporate HFBs with coated fibres seeded with ECs (intraluminally) and glial cells (extraluminally). In an early model developed by Stanness et al [60] ECs and corresponding glial cells from human, rat and bovine sources were cultured successfully in a HFB coated with ProNectin (Table 2) [60]. Morphology and growth patterns were consistent with all cell types, however it was noted that when differing types of ECs and glial cells were cultured, such as human umbilical cord ECs with C6 cell line glial cells, BBB properties were not developed. Poor EC growth in the absence of glial cells within the hollow fibres was observed via low transendothelial resistances and studies assessing the transport of morphine demonstrated permeability ratios to be similar to in vivo, but absolute values to be lower. This was thought to be due to the differences in flow rate patterns in the devices and from in situ. The results supported the use of HFBs in BBB models; however, as bovine aortic endothelial cells + C6 seeded cartridges were used for drug transport studies, utilising human brain ECs in the HFBs would be a natural progression.

Neuhaus et al [61] utilised a commercially available bioreactor from the same manufacturer as Stanness et al, and seeded immortalised porcine brain microvascular endothelial cells (PBMEC/C1-2) intraluminally with the glial cell line C6 cells in the extra capillary space. Medium was pumped through the system applying shear stresses of 2.7-3.9 dyne $\mathrm{m}^{-2}$, mimicking conditions in brain capillaries. Results of cell growth and transport of benzodiazepenes were compared between the transwell and flow based models. They showed that PBMEC/C1-2 cells seeded on the transwell inserts started detaching after 5 days prohibiting the use of transwell systems in long term experiments, whereas growth and morphology of the ECs in the HFB was affected due to exposure to flow, prolonging the survival of the cells within the device. Permeability coefficients of benzodiazepenes were also shown to be lower in the HFB model, presumably due to tighter monolayers and improved barrier functions within the device [61].

The BBB is a very active site in terms of transport, expressing multiple drug transporters to restrict compounds with high affinity for efflux transporters and low transcellular membrane permeability into the CNS. However, due to its complexity, there are very few established in vitro models, and CNS targeted compound analysis relies heavily on in vivo and in silico assessments. P-gp (MDR1) is a predominant efflux transporter in the BBB, capable of limiting the penetration of a wide range of substrates into the brain. For this reason, MDCK-MDR1 cellular bidirectional transport assays are currently used in DMPK screening to assess both CNS penetrating and restricted compounds, as appropriate depending upon target profile [4]. Differences in transporter expression and passive permeability have been shown in 2D static co-culture models (described above). However, investigations have also highlighted interspecies variability, with a 2-fold higher permeability in a rat EC and glial model than in the human counterpart. The limitations of the current transwell model utilising transfected cell lines are its static nature and lack of availability of human cells. However, this system could be improved by using rat ECs and glial cells, to better represent the in vivo environment than is currently available with transfected cell 
lines alone, in order to account for the difference in permeability [62]. Due to the nature of individual transporter testing in current 2D cultures, 3D models exhibiting BBB characteristics could also be utilised for drug-drug interaction studies as the 3D liver models are starting to investigate.

Overall, the outcomes of these models are promising for the use of HFBs in pharmacological applications. However, the human brain is more complex than its rodent counterpart, and although many drug transporter proteins are expressed in rodent ECs [57], primary human ECs and glial cells would ideally be incorporated into an optimised device. This may be difficult to generate for large scale studies as healthy human glial and ECs are scarcely available, so one possible source would be the differentiation of stem cells into these cell types. However, extensive work in stem cell differentiation and characterisation from embryonic and induced pluripotent stem cells is needed, and is not a viable source for models at present. Recreating aspects of the microenvironment of the CNS in terms of ECM proteins surrounding glial cells may also improve performance of the cells within the device.

\section{Progressions in bioartificial kidney (BAK) devices as an in vitro model}

\section{The need for an optimised model from existing clinical devices}

The kidneys are primarily responsible for the excretion of waste products such as urea and ammonia from the body through the urine. They also provide a variety of significant secondary functions through homeostatic, endocrine, immune and metabolic processes.

Chronic kidney disease (CKD) is a growing problem within the UK, with around 1.8 million people diagnosed in England alone. This is putting a growing burden on the NHS, costing over $f 1.4$ billion a year which is largely due to renal replacement therapy e.g. dialysis, 
which showed a $29 \%$ increase in usage from 2002-2008, and complications such as heart disease and stroke [63]. This highlights the need for early diagnosis of the disease, more efficient and cost effective renal replacement therapies, more effective drug treatments and consequently, an optimised kidney model for pharmacological studies.

Existing bioartificial kidney (BAK) devices have been developed primarily as a renal replacement therapy. They incorporate both mechanical and biological processes, pumping haemofiltered blood through a renal assist device (RAD). Coined by Humes et al this device contains renal cells seeded in the lumen of hollow fibres of a standard haemofiltration cartridge [64], contrary to BALs which utilise cells within the ECS. Unlike dialysis, which just provides intermittent filtration, in vitro studies of the BAK device show differentiated active transport of essential nutrients such as glucose, amino acids and sodium bicarbonate, sufficient metabolic activity and important endocrine processes [65]. Although the current bioartificial systems have been utilised for clinical use, there is scope as with the systems mentioned previously to use them as a foundation for many other applications.

There have been two main groups focusing on the development of a BAK device for clinical use. Humes et al developed a device to treat patients with acute renal failure and multiple organ failure with a degree of success, while Saito et al focused on the prevention and treatment of long term complications in patients on maintenance dialysis [66]. Both devices however utilise the same bioartificial component, hollow fibre modules seeded with proximal tubule cells (PTCs), and pass ultrafiltered blood through the module before administering back into the patient (Fig 2). Humes et al [67] utilised commercially available haemofiltration cartridges, with polysulfone (PSF) based fibres seeded with human PTCS (hPTCs). Although confluent monolayers of cells were observed within the fibres [65], Saito et al, concurring with Zink et al [68] has commented on the lack of biocompatibility of PSF and PSF-based membranes for generating a confluent monolayer of cells [66]. The clinical trial undertaken with the BAK device from Humes's group has also been critically assessed, noting the lack of documentation on expected effect size, the incompletion of treatment of patients assigned to CVVH + RAD treatment and the lack of statistical significance of the primary results with comparisons performed as an as-treated rather than an as-randomised intention to treat sample [69].

\section{Cell Sources}

To create an efficient, reliable model of the kidney in situ, a BAK device must incorporate a cell type that can carry out a number of native functions, and so research has been drawn to renal PTCs. These cells perform a variety of renal specific functions including reabsorption, metabolic and transport functions, the secretion of uremic toxins and xenobiotics and performing immunomodulatory functions [70]. Renal PTCs also possess a range of transporters such as organic anion and organic cation transporters for basolateral 
drug uptake and $A B C$ transporters present on the apical surface for luminal excretion into urine. Many of the transporters are polyspecific i.e. accept compounds of different sizes and molecular structures, and have overlapping substrate specificities [71].

Primary hPTCs are required for clinical BAK devices but the sheer number of cells needed (approximately $10^{9}$ renal cells per device) is a major obstacle to their widespread use, driving the search for alternative cell sources. Human PTCs have also been used as a well-characterized in vitro model of the kidney in drug transport studies, owing to the classification of specific carrier proteins on the plasma membrane by substrate specificity and functional assessment, and the prediction of drug-drug interactions based on competitive inhibition for transport [72]. Two transporters, organic anion transporter (OAT) 1 and OAT3 are thought to be the major OATs responsible for the basolateral uptake of various organic ions from the blood in vivo; OAT3 action demonstrated by the mediation of rosuvastatin uptake in vitro in the presence and absence of probenecid, a uricosuric drug [73]. Probenecid has also been shown to be a potent inhibitor of OAT2 and OAT4, where $\mathrm{PGF}_{2 \alpha}$ uptake by OAT2, and estrone-3-sulfate uptake by apically located OAT4, was inhibited in the presence of probenecid. The main uptake transporter of organic cations in hPTCs is thought to be organic cation transporter 2 (OCT2) located on the basolateral membrane. Functionality has been demonstrated in hPTCs by the decrease in uptake of $\mathrm{ASP}^{+}$in the presence and absence of the inhibitor quinine [74]. Although drug-drug interactions for organic cations have been observed in other cell sources such as LLC-PK1 cells, little data on the drug interactions for OCT2 has been documented [75]. Similar to liver, P-gp is documented to transport a wide range of xenobiotics, in particular anti-cancer agents such as methotrexate and cisplatin [76] in hPTCs. However, in hydrophilic statin efflux it has been found to have a minor role compared to the MRP2 and BCRP efflux transporters [73]. Differences between effects of drugs in vivo and in vitro has also been highlighted by the inhibitory effects of KW-3902 and betamipron on OAT4 in vitro, which showed no significant inhibitory effects on OAT4 in vivo [77].

The expression of both phase I (11 CYP enzymes and 3 glutathione $S$-transferases (GSTs)) and phase II (3 UGT and variable expressions of 3 sulfotransferases) drug metabolising enzymes have also been found to be retained within primary hPTC cultures. Furthermore, when grown in a confluent monolayer, which is necessary in current BAK devices, the expression of these enzymes were generally maintained at a measurable level, albeit lower than in the native tissue [78]. Selective drug transporter loss upon primary cell culture has been identified to be a consequence of dedifferentiation. However, recent novel human tubular kidney cell cultures grown on permeable filter supports have been shown to express a wide range of drug transporters due to the co-culture of proximal and distal tubular cells [71]. This finding is concurrent with the increased function from coculture of hepatocytes and non-parenchymal cells in BAL devices. Collectively, these results indicate that primary cultures of hPTCs can metabolize drugs, provide good models for drug interaction studies and benefit the clinical setting when incorporated into BAK devices. 
Although hPTCs do not always represent in vivo functionality, these results could be improved by the incorporation into a dynamic bioreactor, providing a more accurate model of hPTCs in situ.

Using immortalized cell lines eliminates the problem of needing vast numbers of cells for studies. Methods such as cloning, derivation from cancerous cells and viral transfection can all produce genetically stable, but functionally altered cells. Human cells are relatively difficult to immortalize and do not express differentiated features in vitro [65][79]. The established cell line HK-2, generated from the infection of human PTCs with an immortalizing construct from the human papilloma virus, and the more recently developed human kidney proximal tubular cell line (HKC) from exposure of renal epithelial cells to Adeno 12:SV40 hybrid virus, therefore do not provide an adequate replacement for primary cells for use in clinical BAK devices [79]. Other established animal derived cell lines such as LLC-RK1, LLC-PK1 and MDCKII have also provided adequate models for research, but interpretation to the human situation is often difficult due to species differences, especially with regard to transporters and enzymes. Drug transport with human renal cell lines has not been widely researched, possibly due to the substantial loss of differentiated function from the immortalization of human cells, and primary hPTCs or transfected animal cell lines such as MDCKII-MDR1 are more frequently used. This highlights the challenge of generating a physiologically complex, well characterised and validated in vitro cellular model which can replace current FDA recommended cell transport test systems such as P-gp transfected MDCK or LLC-PK1 cells [80].

Porcine PTCs are widely used in kidney research due to their reliability, anatomical and physiological similarity to hPTCs. In preclinical studies, porcine PTCs in a BAK device were shown to tolerate the uremic environment while providing metabolic, reabsorptive and endocrinologic activity in uremic dogs [81], allowing research to further investigate the benefits of BAKs, and progress to hPTC utilization for clinical trials. There are few studies into differences in drug interactions and metabolism between porcine and human PTCs to date, although drug transporter expression on primary porcine PTCs and cell lines are comparative to native human kidney cells (Table 3 ). Both primary and porcine cell lines are readily available and are an established model for drug toxicity, however, an optimized model for drug toxicity would require human PTCs instead of the readily available established porcine model.

Due to their multipotency and self-renewal capabilities, embryonic stem cells may provide a reliable source of PTCs for use in BAK devices when exposed to the right environmental cues [64]. Studies into human ESCs differentiating into renal cells have not been widely undertaken, however preliminary studies have shown integration of undifferentiated and mesoderm- derived ESCs into the stroma and developing nephrons [82]. They have also been shown to express a wide range of early renal markers, and exhibit up-regulation of kidney precursor markers such as EYA1, LIM1, CD24 [83]. The generation of 
the different types of renal cells from human ESCs however still needs to be thoroughly investigated [82]. Due to the sparse studies and various obstacles, drug metabolism and transport by human ESC-derived renal cells has not been documented, but will be essential in any progression of stem cell utilisation towards potential in vitro cell models used in pharmaceutical research.

\section{Device designs}

As mentioned above, the existing devices used for clinical applications utilise haemofiltration cartridges seeded with hPTCs. However for an in vitro model, device design could be optimised. For example the number of cells needed could be greatly decreased due to the reduction of the size of the cartridge. Hollow fibre cartridges could also be greatly optimised, as commercially available modules have varying degrees of biocompatibility. Tailoring fibre materials to different cell types and sources have been thought to improve cell performance, and for primary hPTCs it is thought that some of the membrane properties needed include a hydrophilic, negatively charged adhesive surface [29]. When a variety of commercially used membranes, such as regenerated cellulose (RC), PSF/PVP and polyethersulfone (PES)/PVP coated with ECM, were tested with primary hPTCs, performance of the cells was not improved, indicating that these materials are not suitable for use in BAK devices. The differing properties between cell sources is further highlighted by reports that PSF membranes coated with ECM are able to maintain both primary porcine [84] and LLC-PK1 cell monolayers for 3 weeks after confluency [85].

Coating commercially available fibres with tailored ECM is preferable to tailoring membrane materials due to the ease of assembly and cost effectiveness. Various single and double coatings have been tested, including collagen IV and laminin blends with a variety of growth factors [70]. Single coatings demonstrated little improvement on hPTC performance within the fibre however double coatings of DOPA (3,4-Dihydroxy-Lphenylalanine) and collagen IV on haemocompatible membranes have revealed functional epithelia formed by hPTCs in a HFB [68]. Bioreactor configuration should also be taken into consideration to achieve both native mimicry and produce an optimal environment for the cells to proliferate. Previous bioartificial devices utilising hollow fibre cartridges have encountered problems with the non-uniform distribution of cells and the lack of transport of gases and nutrients [86], so including an oxygenator or aerated medium would need to be considered.

Additionally, in order to mimic the kidney the device would need to include a tubule (hollow fibre) and capillary/blood (extracapillary space) section with shear rates according to native conditions. These would be higher in the ECS (typically $10 \mathrm{dyn} / \mathrm{cm}^{2}$ on endothelial cells in vivo) than in the fibre (typically $1 \mathrm{dyn} / \mathrm{cm}^{2}$ on PTCs in vivo) [87]. This may lead to movement of molecules through the membrane if the monolayer of cells is not tight, and affect cell performance due to varying pressures. However, from previous devices used clincally, no 
loss of membrane integrity has been reported when using different flow rates in the tubule and ECS [67].

Emerging in vitro models have also adhered to the established hollow fibre structure. The Wyss Institute at Harvard University have introduced 'organs on a chip'. These microfluidic devices, in this case 'kidney on a chip' utilise hPTCs seeded within a microfluidic channel apposed to a polyester membrane. The channel is immersed in medium, and a shear stress of $0.2 \mathrm{dyn} / \mathrm{cm}^{3}$ is applied through the channel (Fig 3). Cytoskeletal proteins, tight junction proteins, ion transporters and specific drug transporters (e.g. OCT2) have shown improved results in a fluidic model compared to a static version, and the nephrotoxic compounds such as cisplatin have shown the ability of the microsystem to recapitulate the in vivo toxicity of the drugs. Overall, the system presents a substantial answer to the need of a reliable 3D in vitro model [88]. However, functional characterisation of the drug transporters within the device that are acknowledged to be of clinical importance to drug disposition by the FDA, namely P-gp, BCRP, OCT2, OAT1 and OAT3, should be undertaken to establish an ideal model system [89].

\section{Conclusion and future perspectives}

Bioreactors have been utilised in many different areas of industry and research, and for the progression of in vitro models of 2D cultures and suspensions to 3D constructs mimicking the natural physiological state in situ, they have proven to be crucial. The generation of bioartificial devices provide both the structural and biological aspects, which have been exploited for clinical and research purposes. The most established bioartificial system, the bioartificial liver, is a prime example of the development of a bioreactor designed initially for therapeutic use, being utilised as an in vitro model. From simple perfused bed and hollow fibre bioreactors, focus on the native liver structure and cellular functionality within the device has prompted multi-fibre bundle designs.

In addition to bioreactor design, development of the BBB models have highlighted the importance of cell sources, especially with co-culture of different cell types, within a fluidic system opposed to a static culture. It is understood that primary human cells are the 
gold standard for an in vitro model, however, due to the difficulty of acquisition, BBB models have had to utilise other primary sources. Embryonic stem cells could be a possible answer to the dilemma of availability for the future; however, more research is needed to investigate the difference in properties between primitive and mature human CNS and endothelial cells before incorporation into a device for DMPK investigation.

Bioartificial kidney devices have followed the progression of BAL systems. From development for clinical use as a renal replacement therapy for acute and chronic renal conditions, they are now starting to reveal their potential as in vitro models (Fig 4). Primary human cells have been utilised within the system, and are fairly easy to acquire and maintain, especially with the reduced cell number requirement in a model. Co-culture with distal tubule cells however has not been fully investigated within a BAK device, and functional characterisation of drug transporters crucial for ADME studies have not been undertaken in the existing microfluidic system.

To date, there are no universal criteria laid out to aid the development of an acceptable/suitable bioreactor. However, it is widely accepted that in vivo micro environmental aspects such as cell viability, cell-cell interactions, cell-matrix interactions, tissue architecture and cell oxygenation are vital to give an accurate representation of the physiological state, and consequently the effects of new chemical entities [3]. It is therefore important to bear in mind those factors which are specific to the desired tissue when developing in vitro models for use in pharmaceutical research. Furthermore, it is noticeable that little or no measurements are currently taken from these bioreactor-based devices to help control or monitor cell health or functionality during use. We thus anticipate that, with the continuing advances being made in sensor technology, the next generation of devices will incorporate these to either improve device function or longevity.

Bioartificial systems have started to show great promise in the generation of in vitro models for various organs and disease states. Observations from existing systems are the importance of mimicry of both structure and environments in situ in the bioreactor, the choice of cell and source to model the functions of the organ and essential factors for maintaining cellular function such as oxygen availability and nutrient and metabolite delivery. With these factors in mind, successful models utilising bioreactors can be achieved in the near future and will hopefully provide a better means to predict clinical outcome from in vitro data. 


\section{References}

1. Light, DW (2011) Drug R\&D Costs Questioned. Genetic Engineering \& Biotechnology News 31: 6-7. doi:10.1089/gen.31.13.01.

2. Scherer F. (2011) R\&D Costs and Productivity in Biopharmaceuticals. F. Kennedy School of Government, Harvard University. Available:

http://dash.harvard.edu/bitstream/handle/1/5688848/RWP11-

046_Scherer.pdf?sequence=1. Accessed 10 July 2012.

3. Astashkina A, Mann B, Grainger DW (2012) A critical evaluation of in vitro cell culture models for high-throughput drug screening and toxicity. Pharmacology \& Therapeutics 134: 82-106. doi:10.1016/j.pharmthera.2012.01.001.

4. Ballard P, Brassil P, Bui KH, Dolgos H, Petersson C, et al. (2012) The right compound in the right assay at the right time: an integrated discovery DMPK strategy. Drug Metab Rev 44: 224-252. doi:10.3109/03602532.2012.691099.

5. Barberis A (2002) Cell-Based High-Throughput Screens for Drug Discovery. European Biopharmaceutical Review: 93-96.

6. Gerlach JC, Zeilinger K, Patzer li JF (2008) Bioartificial liver systems: why, what, whither? Regen Med 3: 575-595. doi:10.2217/17460751.3.4.575.

7. Fahrig R, Rupp M, Steinkamp-Zucht A, Bader A (1998) Use of Primary Rat and Human Hepatocyte Sandwich Cultures for Activation of Indirect Carcinogens: Monitoring of DNA Strand Breaks and Gene Mutations in Co-cultured Cells. Toxicol In Vitro 12: 431444.

8. Cai H, Agrawal AK, Putt DA, Hashim M, Reddy A, et al. (2009) Assessment of the renal toxicity of novel anti-inflammatory compounds using cynomolgus monkey and human kidney cells. Toxicology 258: 56-63.

9. Bhatia SN, Balis UJ, Yarmush ML, Toner M (1999) Effect of cell-cell interactions in preservation of cellular phenotype: cocultivation of hepatocytes and nonparenchymal cells. FASEB J 13: 1883-1900.

10. Swift B, Pfeifer ND, Brouwer KLR (2010) Sandwich-cultured hepatocytes: an in vitro model to evaluate hepatobiliary transporter-based drug interactions and hepatotoxicity. Drug Metab Rev 42: 446-471. doi:10.3109/03602530903491881.

11. Hatherell K, Couraud P-O, Romero IA, Weksler B, Pilkington GJ (2011) Development of a three-dimensional, all-human in vitro model of the blood-brain barrier using mono-, co-, and tri-cultivation Transwell models. Journal of Neuroscience Methods 199: 223229. doi:10.1016/j.jneumeth.2011.05.012.

12. Hermanns MI, Unger RE, Kehe K, Peters K, Kirkpatrick CJ (2004) Lung epithelial cell lines in coculture with human pulmonary microvascular endothelial cells: development of an 
alveolo-capillary barrier in vitro. Lab Invest 84: 736-752.

doi:10.1038/labinvest.3700081.

13. Sceats $E$ (n.d.) In Vitro Tissue Models: Working in the Third Dimension. Innovations in Pharmaceutical Technology: 28-32.

14. Elliott NT, Yuan F (2011) A review of three-dimensional in vitro tissue models for drug discovery and transport studies. Journal of Pharmaceutical Sciences 100: 59-74. doi:10.1002/jps.22257.

15. Cuddihy M (2011) 3D Cell Cultures Prevalent in Pharma: Human Predictive Functional Tissue Models Conference. Available: http://3dbiomatrix.com/2011/12/01/3d-cellcultures-prevalent-in-pharma-human-predictive-functional-tissue-models-conference/. Accessed 13 July 2012.

16. Pörtner R, Nagel-Heyer S, Goepfert C, Adamietz P, Meenen NM (2005) Bioreactor design for tissue engineering. Journal of Bioscience and Bioengineering 100: 235-245. doi:10.1263/jbb.100.235.

17. Radisic M, Deen W, Langer R, Vunjak-Novakovic G (2005) Mathematical model of oxygen distribution in engineered cardiac tissue with parallel channel array perfused with culture medium containing oxygen carriers. Am J Physiol Heart Circ Physiol 288: H1278-H1289. doi:10.1152/ajpheart.00787.2004.

18. Wendt D, Riboldi S, Cioffi M, Martin I (2012) Bioreactors in Tissue Engineering: Scientific Challenges and Clinical Perspectives. [Without Title]. Advances in Biochemical Engineering/Biotechnology. Springer Berlin / Heidelberg. pp. 1-27. Available: http://www.springerlink.com/content/421lq0230j814x72/abstract/. Accessed 13 July 2012.

19. Bilello JA, Bauer G, Dudley MN, Cole GA, Drusano GL (1994) Effect of 2', $3^{\prime}$-didehydro$3^{\prime}$-deoxythymidine in an in vitro hollow-fiber pharmacodynamic model system correlates with results of dose-ranging clinical studies. Antimicrob Agents Chemother 38: 1386-1391.

20. Usuludin SBM, Cao X, Lim M (2012) Co-culture of stromal and erythroleukemia cells in a perfused hollow fiber bioreactor system as an in vitro bone marrow model for myeloid leukemia. Biotechnology and Bioengineering 109: 1248-1258.

doi:10.1002/bit.24400.

21. Schmelzer E, Mutig K, Schrade P, Bachmann S, Gerlach JC, et al. (2009) Effect of human patient plasma ex vivo treatment on gene expression and progenitor cell activation of primary human liver cells in multi-compartment 3D perfusion bioreactors for extracorporeal liver support. Biotechnology and Bioengineering 103: 817-827. doi:10.1002/bit.22283.

22. Zeilinger K, Schreiter T, Darnell M, Söderdahl T, Lübberstedt M, et al. (2011) Scaling Down of a Clinical Three-Dimensional Perfusion Multicompartment Hollow Fiber Liver Bioreactor Developed for Extracorporeal Liver Support to an Analytical Scale Device 
Useful for Hepatic Pharmacological In Vitro Studies. Tissue Engineering Part C: Methods 17: 549-556. doi:10.1089/ten.tec.2010.0580.

23. Park J-K, Lee D-H (2005) Bioartificial liver systems: current status and future perspective. J Biosci Bioeng 99: 311-319. doi:10.1263/jbb.99.311.

24. Allen JW, Hassanein T, Bhatia SN (2001) Advances in bioartificial liver devices. Hepatology 34: 447-455. doi:10.1053/jhep.2001.26753.

25. Matsumura KN, Guevara GR, Huston H, Hamilton WL, Rikimaru M, et al. (1987) Hybrid bioartificial liver in hepatic failure: preliminary clinical report. Surgery 101: 99-103.

26. De Bartolo L, Jarosch-Von Schweder G, Haverich A, Bader A (2000) A novel full-scale flat membrane bioreactor utilizing porcine hepatocytes: cell viability and tissue-specific functions. Biotechnol Prog 16: 102-108. doi:10.1021/bp990128o.

27. Naruse K, Sakai Y, Nagashima I, Jiang GX, Suzuki M, et al. (1996) Development of a new bioartificial liver module filled with porcine hepatocytes immobilized on non-woven fabric. Int J Artif Organs 19: 347-352.

28. Sussman NL, Gislason GT, Kelly JH (1994) Extracorporeal liver support. Application to fulminant hepatic failure. J Clin Gastroenterol 18: 320-324.

29. Ni M, Teo JCM, Ibrahim MSB, Zhang K, Tasnim F, et al. (2011) Characterization of membrane materials and membrane coatings for bioreactor units of bioartificial kidneys. Biomaterials 32: 1465-1476. doi:10.1016/j.biomaterials.2010.10.061.

30. Gómez-Lechón MJ, Castell JV, Donato MT (2007) Hepatocytes--the choice to investigate drug metabolism and toxicity in man: in vitro variability as a reflection of in vivo. Chem Biol Interact 168: 30-50. doi:10.1016/j.cbi.2006.10.013.

31. Gómez-Lechón MJ, Donato MT, Castell JV, Jover R (2003) Human hepatocytes as a tool for studying toxicity and drug metabolism. Curr Drug Metab 4: 292-312.

32. Baudoin R, Griscom L, Prot JM, Legallais C, Leclerc E (2011) Behavior of HepG2/C3A cell cultures in a microfluidic bioreactor. Biochemical Engineering Journal 53: 172-181. doi:10.1016/j.bej.2010.10.007.

33. Snouber LC, Bunescu A, Naudot M, Legallais C, Brochot C, et al. (2013) Metabolomicson-a-Chip of Hepatotoxicity Induced by Anticancer Drug Flutamide and Its Active Metabolite Hydroxyflutamide Using HepG2/C3a Microfluidic Biochips. Toxicol Sci 132: 8-20. doi:10.1093/toxsci/kfs230.

34. Wilkening S, Stahl F, Bader A (2003) Comparison of Primary Human Hepatocytes and Hepatoma Cell Line Hepg2 with Regard to Their Biotransformation Properties. Drug Metab Dispos 31: 1035-1042. doi:10.1124/dmd.31.8.1035.

35. Darnell M, Ulvestad M, Ellis E, Weidolf L, Andersson TB (2012) In Vitro Evaluation of Major In Vivo Drug Metabolic Pathways Using Primary Human Hepatocytes and 
HepaRG Cells in Suspension and a Dynamic Three-Dimensional Bioreactor System. J Pharmacol Exp Ther 343: 134-144. doi:10.1124/jpet.112.195834.

36. Ulvestad M, Darnell M, Molden E, Ellis E, Asberg A, et al. (2012) Evaluation of Organic Anion-Transporting Polypeptide 1B1 and CYP3A4 Activities in Primary Human Hepatocytes and HepaRG Cells Cultured in a Dynamic Three-Dimensional Bioreactor System. J Pharmacol Exp Ther 343: 145-156. doi:10.1124/jpet.112.195750.

37. Darnell M, Schreiter T, Zeilinger K, Urbaniak T, Söderdahl T, et al. (2011) Cytochrome P450-dependent metabolism in HepaRG cells cultured in a dynamic three-dimensional bioreactor. Drug Metab Dispos 39: 1131-1138. doi:10.1124/dmd.110.037721.

38. Allen JW, Bhatia SN (2002) Improving the next generation of bioartificial liver devices. Semin Cell Dev Biol 13: 447-454.

39. Patzer JF 2nd, Mazariegos GV, Lopez R, Molmenti E, Gerber D, et al. (1999) Novel bioartificial liver support system: preclinical evaluation. Ann N Y Acad Sci 875: 340-352.

40. Gregory PG, Connolly CK, Toner M, Sullivan SJ (2000) In vitro characterization of porcine hepatocyte function. Cell Transplant 9: 1-10.

41. Donato MT, Castell JV, Gómez-Lechón MJ (1999) Characterization of drug metabolizing activities in pig hepatocytes for use in bioartificial liver devices: comparison with other hepatic cellular models. J Hepatol 31: 542-549.

42. Naik S, Trenkler D, Santangini H, Pan J, Jauregui HO (1996) Isolation and culture of porcine hepatocytes for artificial liver support. Cell Transplant 5: 107-115.

43. Vinken $M$, Vanhaecke $T$, Rogiers $V$ (2012) Primary hepatocyte cultures as in vitro tools for toxicity testing: quo vadis? Toxicology in Vitro 26: 541-544.

doi:10.1016/j.tiv.2012.01.002.

44. Bader A, Knop E, Böker KHW, Crome O, Frühauf N, et al. (1996) Tacrolimus (FK 506) biotransformation in primary rat hepatocytes depends on extracellular matrix geometry. Naunyn-Schmiedeberg's Archives of Pharmacology 353: 461-473. doi:10.1007/BF00261444.

45. Selden C, Hodgson $\mathrm{H}$ (2004) Cellular therapies for liver replacement. Transpl Immunol 12: 273-288. doi:10.1016/j.trim.2003.12.008.

46. Block GD, Locker J, Bowen WC, Petersen BE, Katyal S, et al. (1996) Population expansion, clonal growth, and specific differentiation patterns in primary cultures of hepatocytes induced by HGF/SF, EGF and TGF alpha in a chemically defined (HGM) medium. J Cell Biol 132: 1133-1149.

47. Jasmund I, Langsch A, Simmoteit R, Bader A (2002) Cultivation of Primary Porcine Hepatocytes in an OXY-HFB for Use as a Bioartificial Liver Device. Biotechnology Progress 18: 839-846. doi:10.1021/bp025501y. 
48. Van de Kerkhove MP, Hoekstra R, Chamuleau RAFM, Van Gulik TM (2004) Clinical Application of Bioartificial Liver Support Systems. Ann Surg 240: 216-230. doi:10.1097/01.sla.0000132986.75257.19.

49. Ding Y-T, Shi X-L (2011) Bioartificial liver devices: Perspectives on the state of the art. Front Med 5: 15-19. doi:10.1007/s11684-010-0110-x.

50. Mazariegos GV, Patzer JF, Lopez RC, Giraldo M, DeVera ME, et al. (2002) First Clinical Use of a Novel Bioartificial Liver Support System (BLSS)†. American Journal of Transplantation 2: 260-266. doi:10.1034/j.1600-6143.2002.20311.x.

51. Sauer IM, Neuhaus P, Gerlach JC (2002) Concept for modular extracorporeal liver support for the treatment of acute hepatic failure. Metab Brain Dis 17: 477-484.

52. Ulvestad M, Björquist P, Molden E, Asberg A, Andersson TB (2011) OATP1B1/1B3 activity in plated primary human hepatocytes over time in culture. Biochem Pharmacol 82: 1219-1226. doi:10.1016/j.bcp.2011.07.076.

53. Elsby R, Hilgendorf C, Fenner K (2012) Understanding the Critical Disposition Pathways of Statins to Assess Drug-Drug Interaction Risk During Drug Development: It's Not Just About OATP1B1. Clin Pharmacol Ther 92: 584-598. doi:10.1038/clpt.2012.163.

54. Lau YY, Huang Y, Frassetto L, Benet LZ (2007) effect of OATP1B transporter inhibition on the pharmacokinetics of atorvastatin in healthy volunteers. Clin Pharmacol Ther 81 : 194-204. doi:10.1038/sj.clpt.6100038.

55. Abbott NJ, Rönnbäck L, Hansson E (2006) Astrocyte-endothelial interactions at the blood-brain barrier. Nature Reviews Neuroscience 7: 41-53. doi:10.1038/nrn1824.

56. Huber JD, Egleton RD, Davis TP (2001) Molecular physiology and pathophysiology of tight junctions in the blood-brain barrier. Trends in Neurosciences 24: 719-725. doi:10.1016/S0166-2236(00)02004-X.

57. Cucullo L, Aumayr B, Rapp E, Janigro D (2005) Drug delivery and in vitro models of the blood-brain barrier. Curr Opin Drug Discov Devel 8: 89-99.

58. Hori S, Ohtsuki S, Tachikawa M, Kimura N, Kondo T, et al. (2004) Functional expression of rat $A B C G 2$ on the luminal side of brain capillaries and its enhancement by astrocytederived soluble factor(s). J Neurochem 90: 526-536. doi:10.1111/j.14714159.2004.02537.x.

59. Cucullo L, McAllister MS, Kight K, Krizanac-Bengez L, Marroni M, et al. (2002) A new dynamic in vitro model for the multidimensional study of astrocyte-endothelial cell interactions at the blood-brain barrier. Brain Res 951: 243-254.

60. Stanness KA, Westrum LE, Fornaciari E, Mascagni P, Nelson JA, et al. (1997) Morphological and functional characterization of an in vitro blood-brain barrier model. Brain Research 771: 329-342. doi:10.1016/S0006-8993(97)00829-9. 
61. Neuhaus W, Lauer R, Oelzant S, Fringeli UP, Ecker GF, et al. (2006) A novel flow based hollow-fiber blood-brain barrier in vitro model with immortalised cell line PBMEC/C1-2. J Biotechnol 125: 127-141. doi:10.1016/j.jbiotec.2006.02.019.

62. Lacombe O, Videau O, Chevillon D, Guyot A-C, Contreras C, et al. (2011) In Vitro Primary Human and Animal Cell-Based Blood-Brain Barrier Models as a Screening Tool in Drug Discovery. Mol Pharmaceutics 8: 651-663. doi:10.1021/mp1004614.

63. Taylor L (2012) England's “ $£ 1.4 B$ price tag for kidney disease”. Pharma Times Online. Available: http://www.pharmatimes.com/Article/12-0809/England_s_\%C2\%A31_4B_price_tag_for_kidney_disease.aspx.

64. Humes HD, Szczypka MS (2004) Advances in cell therapy for renal failure. Transpl Immunol 12: 219-227. doi:10.1016/j.trim.2003.12.015.

65. Humes HD, Mackay SM, Funke AJ, Buffington DA (1999) Tissue engineering of a bioartificial renal tubule assist device: In vitro transport and metabolic characteristics. Kidney International 55: 2502-2514. doi:10.1046/j.1523-1755.1999.00486.x.

66. Saito A, Aung T, Sekiguchi K, Sato Y (2006) Present status and perspective of the development of a bioartificial kidney for chronic renal failure patients. Ther Apher Dial 10: 342-347. doi:10.1111/j.1744-9987.2006.00387.x.

67. Humes HD, Weitzel WF, Bartlett RH, Swaniker FC, Paganini EP, et al. (2004) Initial clinical results of the bioartificial kidney containing human cells in ICU patients with acute renal failure. Kidney Int 66: 1578-1588. doi:10.1111/j.1523-1755.2004.00923.x.

68. Oo ZY, Deng R, Hu M, Ni M, Kandasamy K, et al. (2011) The performance of primary human renal cells in hollow fiber bioreactors for bioartificial kidneys. Biomaterials 32: 8806-8815. doi:10.1016/j.biomaterials.2011.08.030.

69. Chertow GM, Waikar SS (2008) Toward the Promise of Renal Replacement Therapy. Journal of the American Society of Nephrology 19: 839 -840. doi:10.1681/ASN.2008030291.

70. Zhang H, Tasnim F, Ying JY, Zink D (2009) The impact of extracellular matrix coatings on the performance of human renal cells applied in bioartificial kidneys. Biomaterials 30 : 2899-2911. doi:10.1016/j.biomaterials.2009.01.046.

71. Masereeuw R, Russel FGM (2010) Therapeutic implications of renal anionic drug transporters. Pharmacol Ther 126: 200-216. doi:10.1016/j.pharmthera.2010.02.007.

72. Lash LH, Putt DA, Cai H (2006) Membrane transport function in primary cultures of human proximal tubular cells. Toxicology 228: 200-218. doi:10.1016/j.tox.2006.08.035.

73. Verhulst A, Sayer R, De Broe ME, D’Haese PC, Brown CDA (2008) Human proximal tubular epithelium actively secretes but does not retain rosuvastatin. Mol Pharmacol 74: 1084-1091. doi:10.1124/mol.108.047647. 
74. Pietig G, Mehrens T, Hirsch JR, Çetinkaya I, Piechota H, et al. (2001) Properties and Regulation of Organic Cation Transport in Freshly Isolated Human Proximal Tubules. J Biol Chem 276: 33741-33746. doi:10.1074/jbc.M104617200.

75. Zhang L, Brett CM, Giacomini KM (1998) Role of Organic Cation Transporters in Drug Absorption and Elimination. Annual Review of Pharmacology and Toxicology 38: 431460. doi:10.1146/annurev.pharmtox.38.1.431.

76. Leslie EM, Deeley RG, Cole SPC (2005) Multidrug resistance proteins: role of Pglycoprotein, MRP1, MRP2, and BCRP (ABCG2) in tissue defense. Toxicology and Applied Pharmacology 204: 216-237. doi:10.1016/j.taap.2004.10.012.

77. Enomoto A, Takeda M, Shimoda M, Narikawa S, Kobayashi Y, et al. (2002) Interaction of Human Organic Anion Transporters 2 and 4 with Organic Anion Transport Inhibitors. J Pharmacol Exp Ther 301: 797-802. doi:10.1124/jpet.301.3.797.

78. Lash LH, Putt DA, Cai H (2008) Drug metabolism enzyme expression and activity in primary cultures of human proximal tubular cells. Toxicology 244: 56-65. doi:10.1016/j.tox.2007.10.022.

79. Racusen LC, Monteil C, Sgrignoli A, Lucskay M, Marouillat S, et al. (1997) Cell lines with extended in vitro growth potential from human renal proximal tubule: characterization, response to inducers, and comparison with established cell lines. J Lab Clin Med 129: 318-329.

80. Szakács G, Váradi A, Özvegy-Laczka C, Sarkadi B (2008) The role of ABC transporters in drug absorption, distribution, metabolism, excretion and toxicity (ADME-Tox). Drug Discovery Today 13: 379-393. doi:10.1016/j.drudis.2007.12.010.

81. Humes HD, Mackay SM, Funke AJ, Buffington DA (1997) The bioartificial renal tubule assist device to enhance CRRT in acute renal failure. Am J Kidney Dis 30: S28-31.

82. Dolt KS (2009) 14-P007 Differentiation of human embryonic stem cells towards renal progenitors. Mechanisms of Development 126: 2.

83. Batchelder CA, Lee CCI, Matsell DG, Yoder MC, Tarantal AF (2009) Renal ontogeny in the rhesus monkey (Macaca mulatta) and directed differentiation of human embryonic stem cells towards kidney precursors. Differentiation 78: 45-56. doi:10.1016/j.diff.2009.05.001.

84. Humes HD, Fissell WH, Weitzel WF, Buffington DA, Westover AJ, et al. (2002) Metabolic replacement of kidney function in uremic animals with a bioartificial kidney containing human cells. Am J Kidney Dis 39: 1078-1087. doi:10.1053/ajkd.2002.32792.

85. Sato Y, Terashima M, Kagiwada N, Tun T, Inagaki M, et al. (2005) Evaluation of proliferation and functional differentiation of LLC-PK1 cells on porous polymer membranes for the development of a bioartificial renal tubule device. Tissue Eng 11: 1506-1515. doi:10.1089/ten.2005.11.1506. 
86. Nedredal GI, Elvevold K, Ytreb $\varnothing$ LM, Fuskevåg O-M, Pettersen I, et al. (2007) Significant contribution of liver nonparenchymal cells to metabolism of ammonia and lactate and cocultivation augments the functions of a bioartificial liver. American Journal of Physiology - Gastrointestinal and Liver Physiology 293: G75 -G83.

doi:10.1152/ajpgi.00245.2006.

87. Duan Y, Gotoh N, Yan Q, Du Z, Weinstein AM, et al. (2008) Shear-Induced Reorganization of Renal Proximal Tubule Cell Actin Cytoskeleton and Apical Junctional Complexes. PNAS 105: 11418-11423. doi:10.1073/pnas.0804954105.

88. Jin Jang K, Ingber D (2011) HUMAN KIDNEY PROXIMAL TUBULE-ON-A-CHIP FOR DRUG TRANSPORTER STUDIES AND NEPHROTOXICITY ASSESSMENT Seattle, Washington. Available: http://www.rsc.org/images/LOC/2011/PDFs/Papers/502_0844.pdf. Accessed 12 August 2012.

89. Research C for DE and (n.d.) Drug Interactions \& Labeling - Drug Development and Drug Interactions: Table of Substrates, Inhibitors and Inducers. Available: http://www.fda.gov/Drugs/DevelopmentApprovalProcess/DevelopmentResources/Dru gInteractionsLabeling/ucm093664.htm\#major. Accessed 12 August 2012. 


\section{Figure legends:}

Figure 1: (a) Smallest capillary unit with 2 medium capillaries that are independently perfused (red and blue) and one gas capillary (yellow); cells are cultured within the extracapillary space (cell compartment). (b) The bioreactor consists of 3 interwoven capillary bundles each made of multiple hollow fibre capillaries for counter-current medium perfusion (red and blue) and gas supply (yellow), which allows decentralised nutrient and $\mathrm{O}_{2} / \mathrm{CO}_{2}$ exchange with low gradients. (c) Down-scaling of the clinical- scale bioreactor prototype with a cell compartment volume of $800 \mathrm{ml}$ was realised by reducing the length and number of capillary layers in 2 axes of 3D space within the bioreactor, resulting in a laboratory- scale bioreactor with a cell compartment volume of $8 \mathrm{ml}$ and a further downscaled model with a cell compartment volume of $2 \mathrm{ml}$. Figure and caption taken from Zeilinger et al [22]

Figure 2: Schematic diagram of (a) bioartificial kidney device used for the treatment of acute renal failure developed by Humes et al (b) bioartificial kidney device developed as a renal replacement therapy for chronic renal failure by Saito et al. Based on device layouts from [67], [66]. The devices have similar components and configurations; however the device by Saito et al incorporates a continuous haemofilter for continuous treatment.

Figure 3: Schematic of human kidney proximal tubule-on-a-chip in the form of multi-layer microfluidic device by integrating a polydimethylsiloxane (PDMS) microfluidic channel, a porous membrane, and a PDMS reservoir. Human primary proximal tubule cells were cultured on the device. Modified with permission from Jin Jang et al [88].

Figure 4: Key aspects from the progression of bioreactor based in vitro models and future developments [22] [61] [68]. 


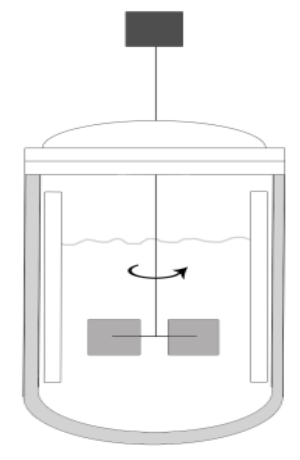

\author{
- Induces \\ movement of oxygen and \\ nutrient within culture \\ medium \\ - Easy to scale up
}

Pros:

Cons:

Uses:

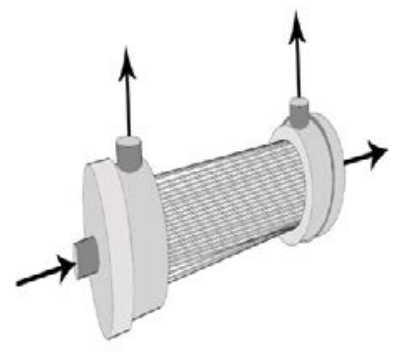

Perfused beds/Scaffolds

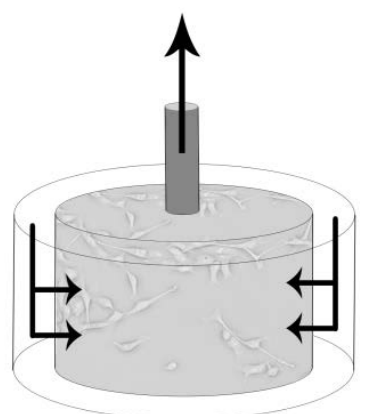

Growth of cartilage constructs
- Non-uniform cell distribution

- Fibre membrane can act as a physical

transport barrier

\section{- Potential for immunoisolation \\ - Perception that cells are protected from shear \\ - Efficient surface area for attachment}

Pros:

Cons:

Uses:

\section{Generation of a} bioartificial liver support system

$$
\begin{array}{cc}
\text { - Uniform cell distribution } & \text { - Complex scale-up } \\
\text { - Good distribution of } & \text { - Cells exposed to shear } \\
\text { nutrients and gas transfer } & \text { stresses } \\
\text { - Stable microenvironment } & \text { - Low surface area to } \\
& \text { volume ratio }
\end{array}
$$

Cartilage construct engineering from chondrocyte seeded scaffolds 

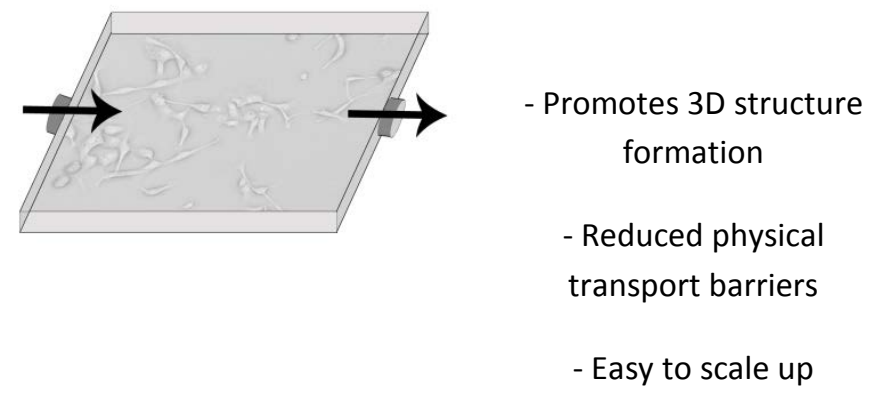

- Easy to scale up

- Nutrient and oxygen

transfer issues

Table 1: Bioreactor designs and uses in tissue engineering applications 
Table 2: Performance of various cell types within the HFB in the generation of an in vitro BBB model

Endothelial Cell (EC)

endothelial cells (RBMEC)

Rat brain astrocytes (RBA)

Human brain endothelial Human foetal astrocytes cells

Bovine aortic endothelial cells
30

[63]

Ref

Not reported

[63]

C6 glial cell line

30

[63] 
Table 3: Drug transporter orthologues present on MDCKII and LLC-PK1 cell lines and primary porcine PTCs ${ }^{1}$

\begin{tabular}{|c|c|c|c|c|c|c|}
\hline Transporter Family & $\begin{array}{c}\text { Gene } \\
\text { Product }\end{array}$ & Location & $\begin{array}{c}\text { MDCK } \\
\text { II }\end{array}$ & $\begin{array}{l}\text { LLC- } \\
\text { PK1 }\end{array}$ & $\begin{array}{c}\text { Primary } \\
\text { Porcine Cells }\end{array}$ & Ref \\
\hline \multirow[t]{4}{*}{ Organic anion transporters } & $\begin{array}{c}\text { OAT1 } \\
\text { (SLC22A6) }\end{array}$ & Basolateral & $x$ & $x$ & $\sim$ & $\begin{array}{c}{[85][86][87]} \\
{[88]}\end{array}$ \\
\hline & $\begin{array}{c}\text { OAT2 } \\
\text { (SLC22A7) }\end{array}$ & Basolateral & & & & {$[85][86]$} \\
\hline & $\begin{array}{c}\text { OAT3 } \\
\text { (SLC22A8) }\end{array}$ & Basolateral & $\mathrm{X}$ & $x$ & $\sqrt{ }$ & $\begin{array}{c}{[85][86][87]} \\
{[88]}\end{array}$ \\
\hline & $\begin{array}{l}\text { OATP1A2 } \\
\text { (SLCO1A2) }\end{array}$ & Apical & $x$ & $x$ & $+/-$ & [88] [89] \\
\hline \multirow[t]{7}{*}{ ATP binding cassette $(A B C)$ transporters } & $\begin{array}{c}\text { MRP1 } \\
\text { (ABCC1) }\end{array}$ & Basolateral & $\sqrt{ }$ & $\sqrt{ }$ & $\sqrt{ }$ & $\begin{array}{c}{[85][86][87]} \\
{[88][89]}\end{array}$ \\
\hline & $\begin{array}{c}\text { MRP5 } \\
\text { (ABCC5) }\end{array}$ & & & & & [85] [86] [87] \\
\hline & $\begin{array}{c}\text { MRP2 } \\
\text { (ABCC2) } \\
\text { MRP4 } \\
\text { (ABCC4) }\end{array}$ & 更 & $\sqrt{ }$ & $\sqrt{ }$ & $\sqrt{ }$ & $\begin{array}{c}{[85][86][87]} \\
{[88][89]} \\
{[85][86][87]}\end{array}$ \\
\hline & $\begin{array}{c}\text { MRP3 } \\
\text { (ABCC3) }\end{array}$ & Basolateral & $\sqrt{ }$ & & & {$[85][86]$} \\
\hline & $\begin{array}{c}\text { MRP6 } \\
\text { (ABCC6) }\end{array}$ & Basolateral & $\sqrt{ }$ & & & {$[85][86]$} \\
\hline & $\begin{array}{c}\text { MDR1 } \\
\text { (ABCB1) }\end{array}$ & Apical & $\sqrt{ }$ & $\sqrt{ }$ & $\sqrt{ }$ & $\begin{array}{c}{[85][86][87]} \\
{[89]}\end{array}$ \\
\hline & $\begin{array}{c}\text { BCRP } \\
(A B C G 2)\end{array}$ & Apical & $\sqrt{ }$ & $\sqrt{ }$ & $x$ & {$[85]$} \\
\hline Organic cation transporters & $\begin{array}{c}\text { OCT1 } \\
\text { (SLC22A1) }\end{array}$ & Basolateral & $x$ & $x$ & $\sim$ & {$[85][86][87]$} \\
\hline
\end{tabular}


(SLC22A2)

OCT3 Basolateral

(SLC22A3)

Carnitine/organic cation transporters OCTN1

Apical

(SLC22A4)

OCTN2

Apical

[85] [86] [87]

(SLC22A5)

Organic anion transporting polypeptides

OATP4C1 Basolateral

(SLCO4C1)

Peptide transporters PEPT1

Apical

X

[85] [86] [87]

(SLC5A1)

PEPT2

Apical

$X$

X

[85] [86] [87]

(SLC5A2)

Multidrug and toxic compound extrusion

MATE1

Apical transporters

(SLC47A1)

MATE2-K Apical

(SLC47A2)

\footnotetext{
${ }^{1}$ Human drug transporter orthologues present on the cell lines and primary cells. Blank fields indicate no presence of transporters on the cells. Abbreviations: $V$, present; $X$, absent; +/-, only detectable after 35 cycles of PCR; , only present in freshly isolated samples.
} 

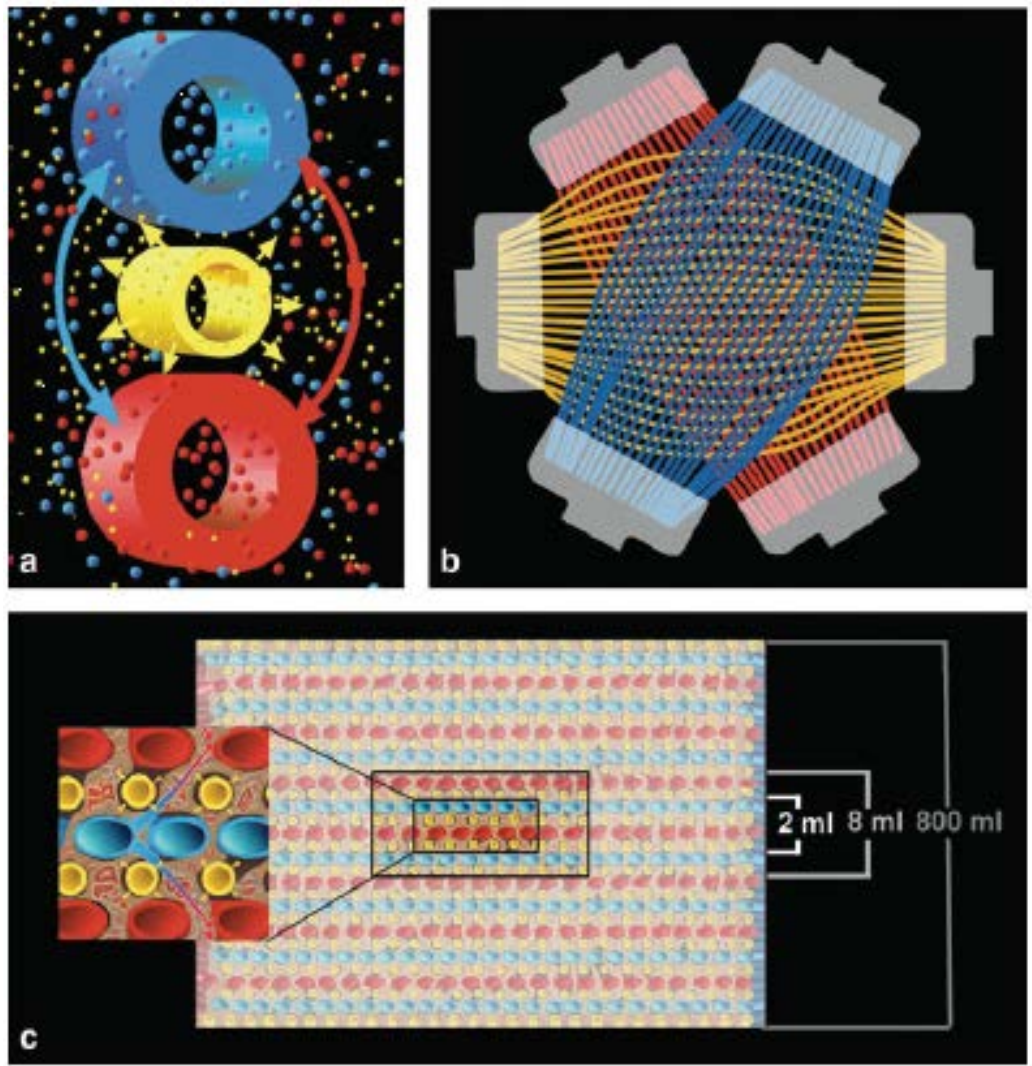

Fig 1. 


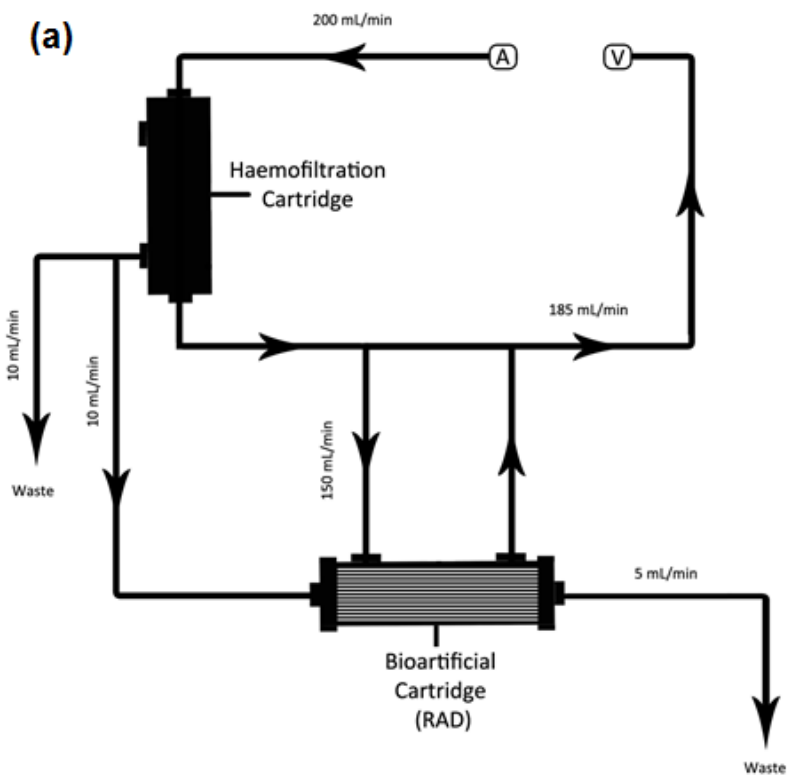

(b)

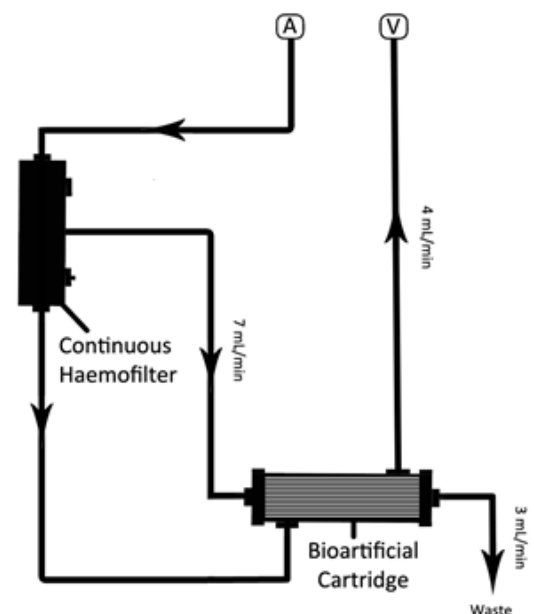

Fig 2. 


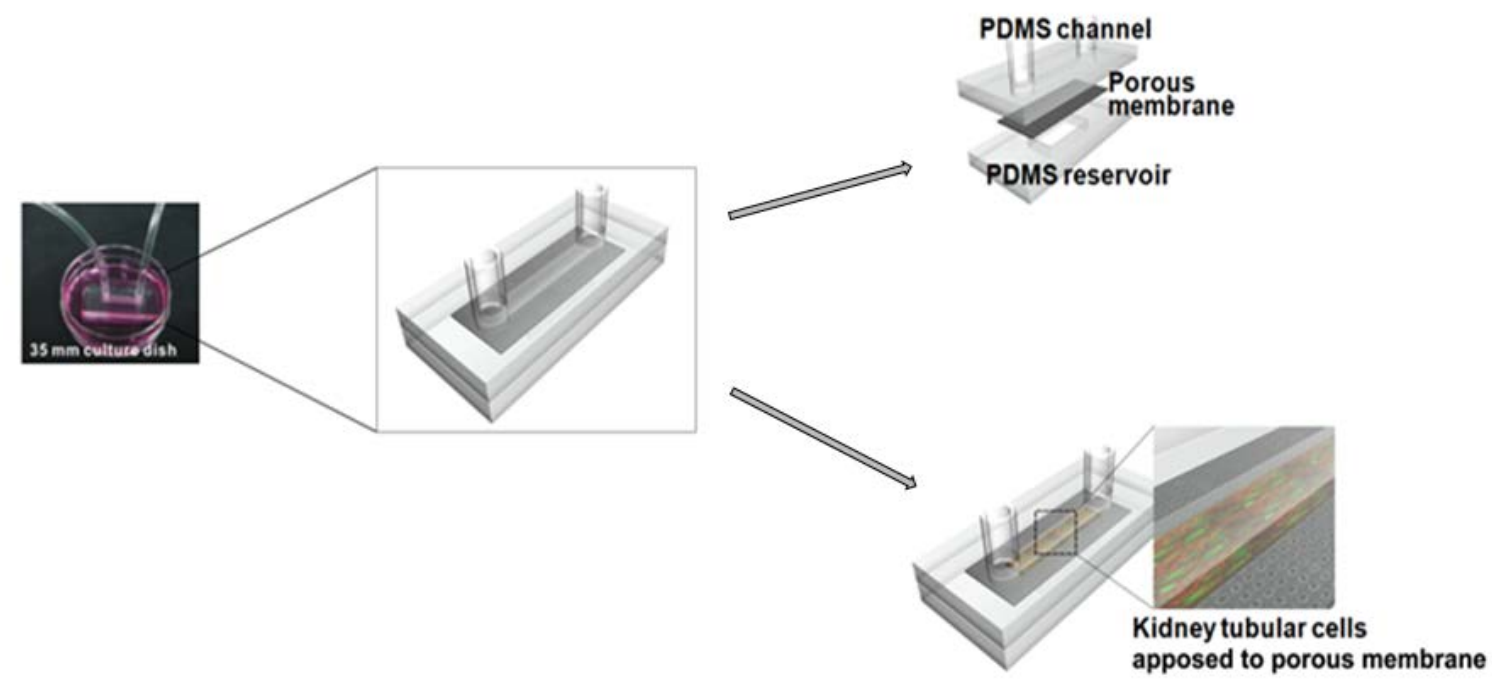

Fig 3.

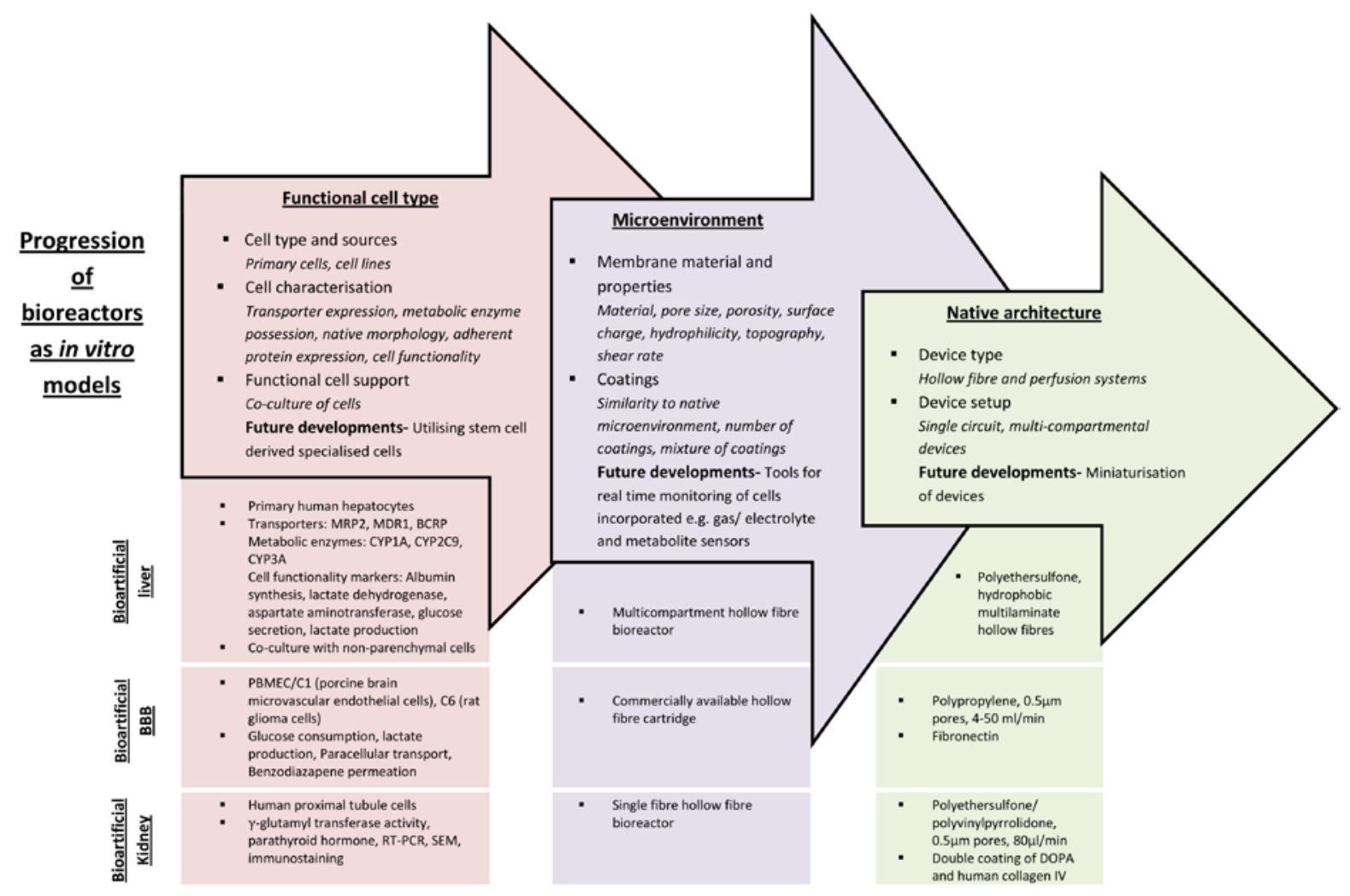

Fig. 4 